\title{
Ulceration of diabetic foot treated with cutaneus flap from fingers
}

\author{
V. Crihana
}

Department of General Surgery, Ilfov County Hospital, Bucharest, Romania

Corresponding author:

Viorel Crihana, MD Surgeon

Department of General Surgery, Ilfov

County Hospital, Bucharest, Romania

E-mail: viorel_crihana@yahoo.com

\section{ABSTRACT}

Diabetes complicated with neuropathy, vasculopathy, bone distortions may lead to the appearance of extended necrosis of the foot, witch surgically treated, could result in tissue loss associated with skin deficit. One of the variants to cover these defects is the plasty using flaps of skin kept from the plantar or dorsal part of amputated fingers. In order to assure the success of these techniques an assessment of the type of diabetic foot is required (neuropathic, neuroischemic) and the type of lesion, satisfy the condition that the flap of skin is well vascularized, and the application bed is well debrided.

Key words: diabetic foot, reconstructive surgery, neuropathy, lower-extremity flap

\section{INTRODUCTION}

The prevalence of diabetes is increasing, according to WHO the number of patients with diabetes will double by 2030 , and about $6 \%$ of patients may develop diabetic foot ulcers and $15 \%$ of them reach major amputations (50\% fatal in 5 years) (1).

Various types of ulcerative lesions may occur in the diabetic foot, affected at microvascular level, over which superimposed infection lead to a number of difficulties in solving these surgical patients.

Therefore, diabetic foot lesions must be thoroughly investigated and subsequently better classified according to the predominant form of vascular impairment (neuropathy with impaired microvascular and neuroichemic - with major macrovascular damage) and classification by type of ulceration according to University of Texas (table 1) (1,2). Going over this step may influence therapeutic approach and can result in unwanted results.

Various types of diabetic foot ulcers (gangrene, osteitis, phlegmons, etc.) can lead to significant loss of tissue (fingers or anterior-foot), surgical treatment involves excision of necrotic and infected tissue, resulting in significant skin defects with subsequent healing cumbersome. 
Classification of diabetic foot ulcers (University of Texas) Table 1

\begin{tabular}{|c|c|c|c|c|}
\hline \multicolumn{5}{|c|}{ Grade } \\
\hline Stage & 0 & I & II & III \\
\hline A & $\begin{array}{l}\text { Pre - or Postulcerative injury, } \\
\text { completely epithelialized }\end{array}$ & $\begin{array}{l}\text { Superficial lesions } \\
\text { That do not involve tendons, } \\
\text { capsule or bone }\end{array}$ & $\begin{array}{l}\text { Penetrating ulcers into } \\
\text { tendon or capsules }\end{array}$ & $\begin{array}{l}\text { Penetrating ulcers into } \\
\text { bone or joints }\end{array}$ \\
\hline$B$ & + infection & + infection & + infection & + infection \\
\hline C & + ischemia & + ischemia & + ischemia & + ischemia \\
\hline D & $\begin{array}{l}+ \text { infection } \\
+ \text { infection }\end{array}$ & $\begin{array}{l}+ \text { ischemia } \\
+ \text { ischemia }\end{array}$ & $\begin{array}{l}\text { + infection } \\
+ \text { infection }\end{array}$ & $\begin{array}{l}+ \text { ischemia } \\
+ \text { ischemia }\end{array}$ \\
\hline
\end{tabular}

The absence of skin, the gateway to germs, promotes infection, occurring subsequent complications requiring additional amputations worsening prognosis.

A surgical alternative to cover this lack of tissue is to preserve viable skin flaps from the face or dorsal planting of amputated fingers with which to cover these solutions of continuity. These flaps are composed of epidermis, dermis and subcutaneous tissue. Vascularization is provided by the arterial plexus intradermal or subdermal crossing the skin pedicle (3). Surgical techniques for keeping these flaps involve atraumatic method to avoid compromising the vasculature (avoid crushing with forceps, to avoid using electrocautery) and a thorough hemostasis to prevent the formation of a hematoma $(3,6,7)$. Also to be avoided suture tension that produces ischemia of the flap (3).

Surgical treatment of diabetic foot lesion should involve removal of necrotic tissue and infected skin so that the skin flap covers viable, uninfected tissue $(1,5)$.

When not sure of this, the surgeon may delay covering the fault, preserving the skin flap and performing debridement of necrotic tissue daily up to complete cleaning and subsequent coating solution with cutaneous flap.

\section{CASE REPORT}

BD 53 y-o patient, known with type 2 diabetic for 12 years, is hospitalized in our department with right toe swelling, ulceration stretched to the planting face of the finger, which externalizes pus, swelling of the right plantar region, with local inflammatory phenomena present, centered by a small plantar incision (done in other surgical service), with drainage tube inserted through a subcutaneous tunnel to the right big toe.

Palpation reveals pulsations of the pedious and tibial arteries, bilaterally.

Ankle-brachial pressure index $=1$.

From the wound pus is collected and sent to
Bacterial culture and sensitivity.

Biological samples taken show blood glicemia of $300 \mathrm{mg} / \mathrm{dL}$ and leukocytosis $\left(17,000 / \mathrm{mm}^{3}\right)$.

Diabetological consult, recommends switching to insulin therapy in four doses for better glucose control .

Right leg radiography (figures 1,2) showed lesions in the distal phalanx suggesting osteitis of the right toe.

Doppler examination of lower limbs describes normal blood flow in large vessels.

Clinical and laboratory investigations lead to the following diagnosis:

- Fistulising Osteitis of the distal phalanx of the right toe.

- Wet gangrene with extensive skin necrosis of the right toe.

- Right plantar Phlegmon insufficiently drained.

- Unbalanced Type 2 Diabetes.

- Stage III B - Texas classification.

Treatment is established Cefort 3g / day and Metronidazole Injection $2 \mathrm{~g} /$ day - in infusion.

Emergency surgical treatment was applied, practicing trans-phalangian proximal amputation with excision of the distal phalanx and partially of the proximal phalanx, ligamentous apparatus, sesamoid bones, necrotic tissues (figure 6) with preservation of skin flaps from the dorsal face of the big toe (figure 7), with which will cover the skin defect due to necrosis of the plantar skin (figure 7).

A longitudinal tegumental incision is performed through healthy tissue, with excision of necrotic tissue and plantar fascia (figure 8). At the end the surgeon passes some monofilament 4-0 sutures in order to fix skin flaps to defective areas in the tegument (figure 9), while rebuilding a new form of the amputated toe.

Evolution was favorable, with healing, requiring several small tissue necrectomy in the postoperative days.

Bacteriological examination - presence of Klebsiella sensitive to treatment with Cefort (ceftriaxone) and quinolone - tratment was administrated for 7 post- 


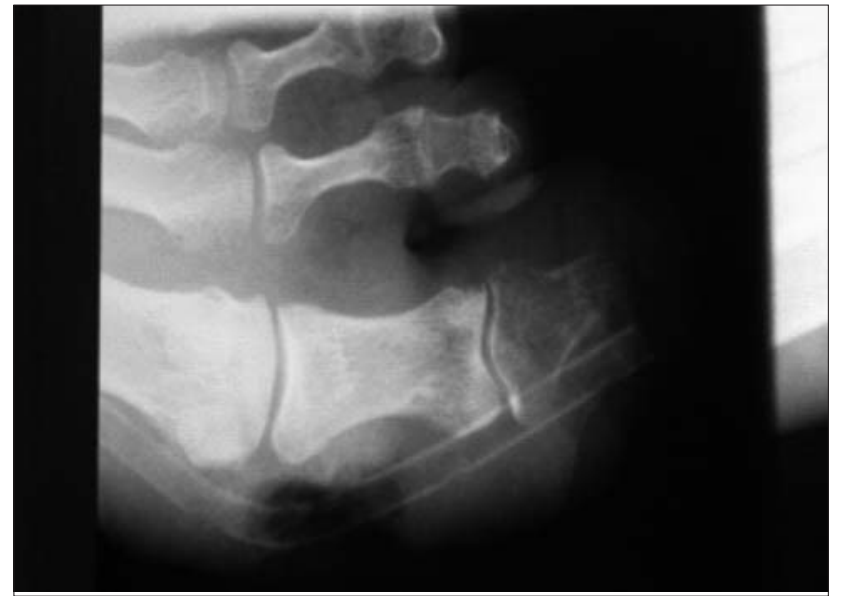

Figure 1

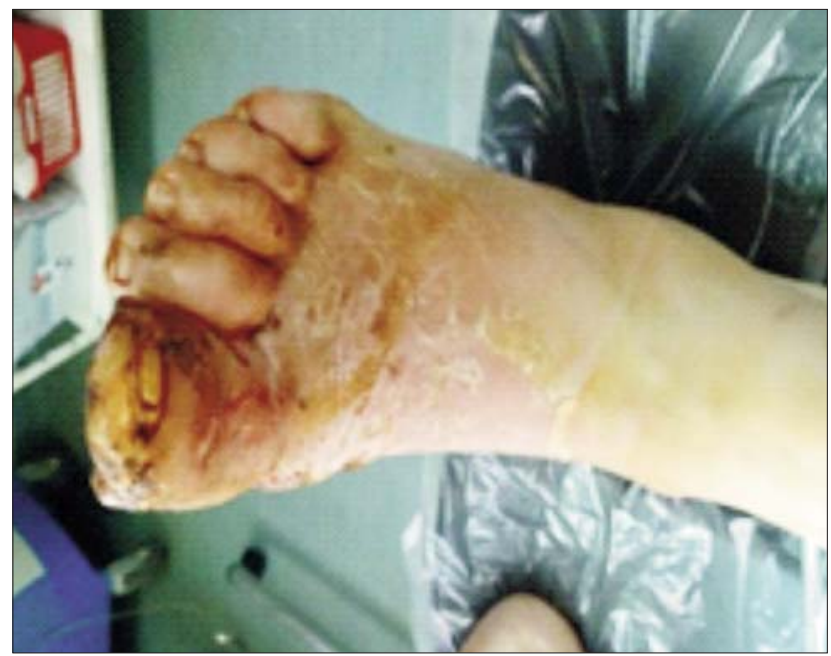

Figure 3

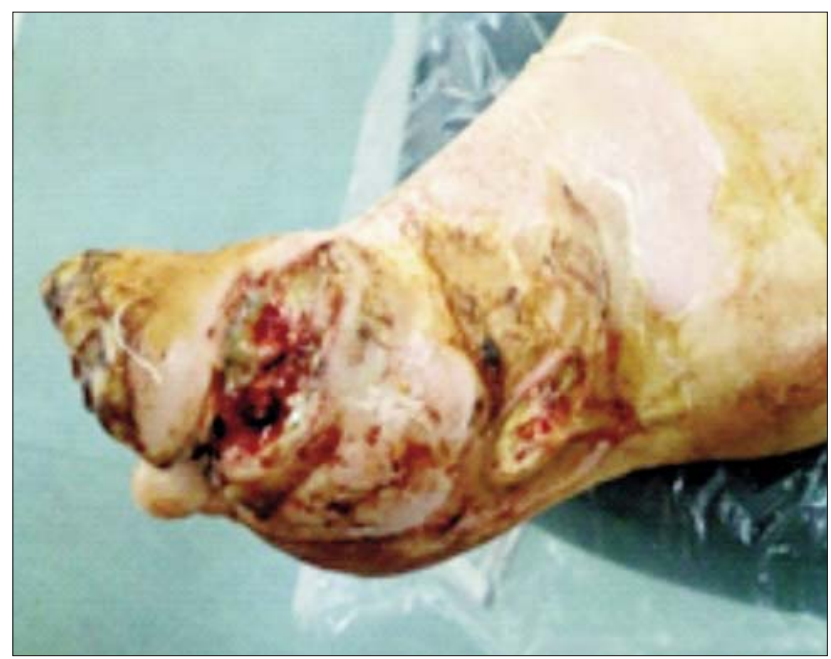

Figure 5

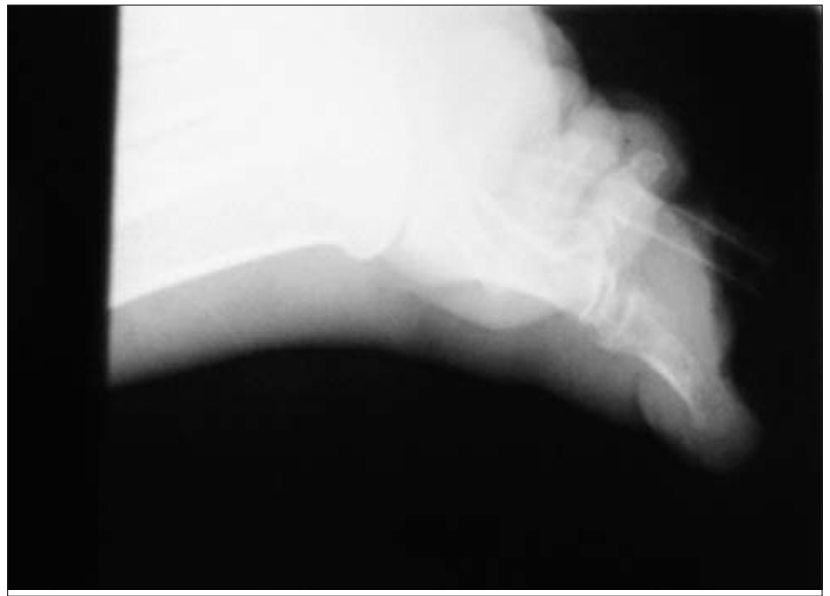

Figure 2

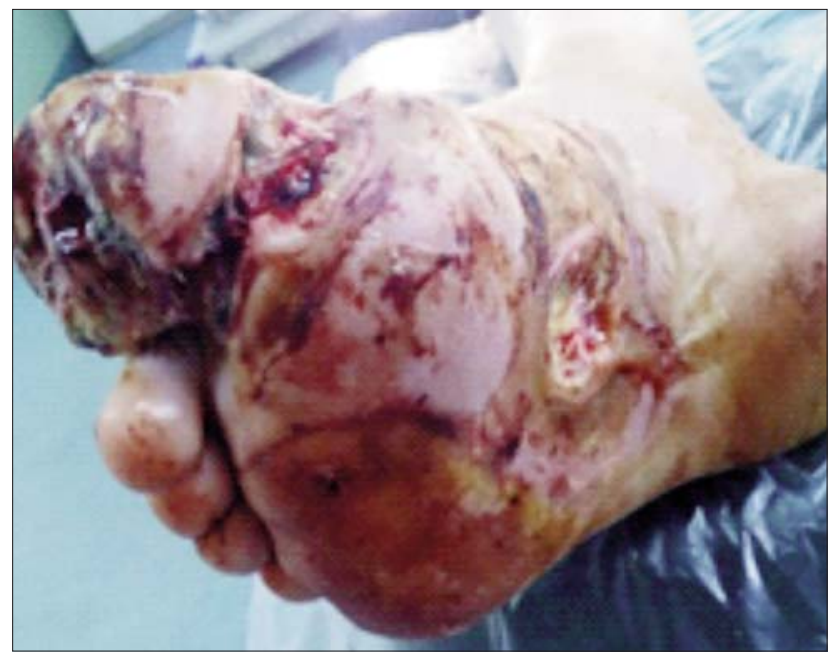

Figure 4

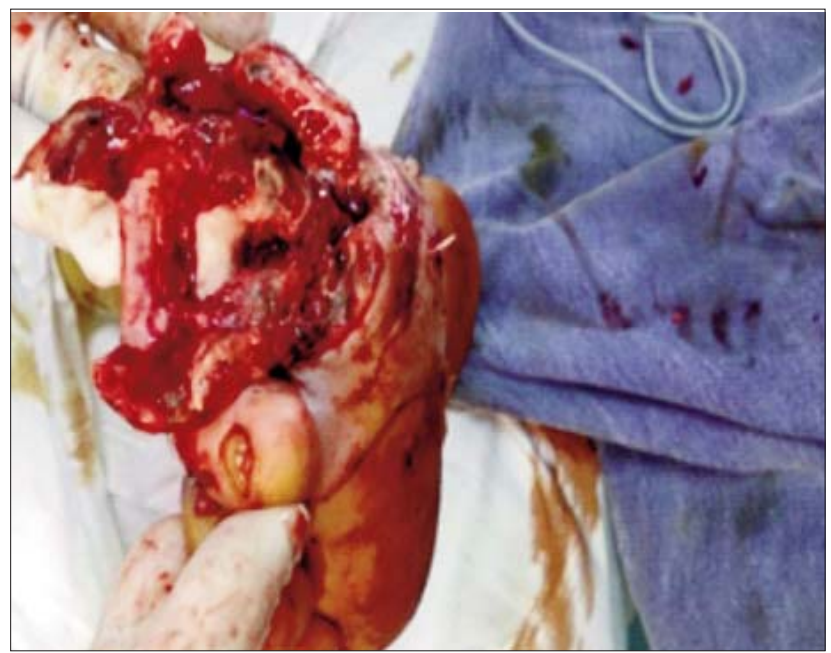

Figure 6 


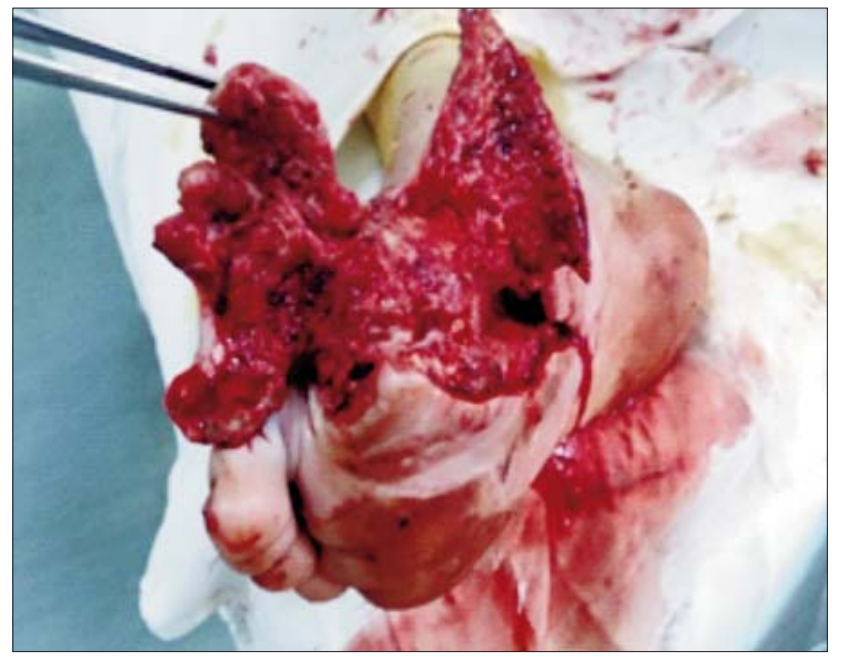

Figure 7

operative days i.v. perfusion with Cefort $3 \mathrm{~g} /$ day, and Ciprofloxacin 2 tablets/day for 10 days.

The patient was discharged on the 7th postoperative day, healed, with periodical reassessments after 23 days.

\section{RESULTS AND DISCUSSIONS}

Postoperative outcome of the patient was good with almost complete healing at three weeks postoperatively, with good functional results but also with a favorable aesthetic result obtained by the reconstruction of the big toe. Surgical intervention, without using that skin flap in order to cover the tegumental defect, would have led to a slow recovery (several months) and wound exposure to external factors with the occurrence of possible complications.
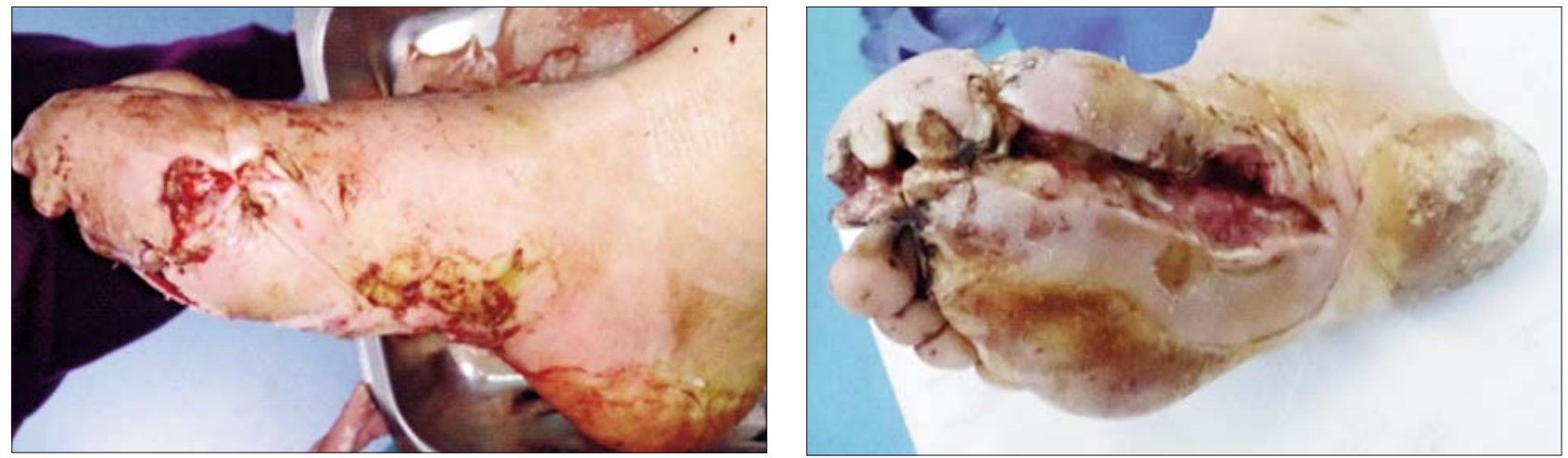

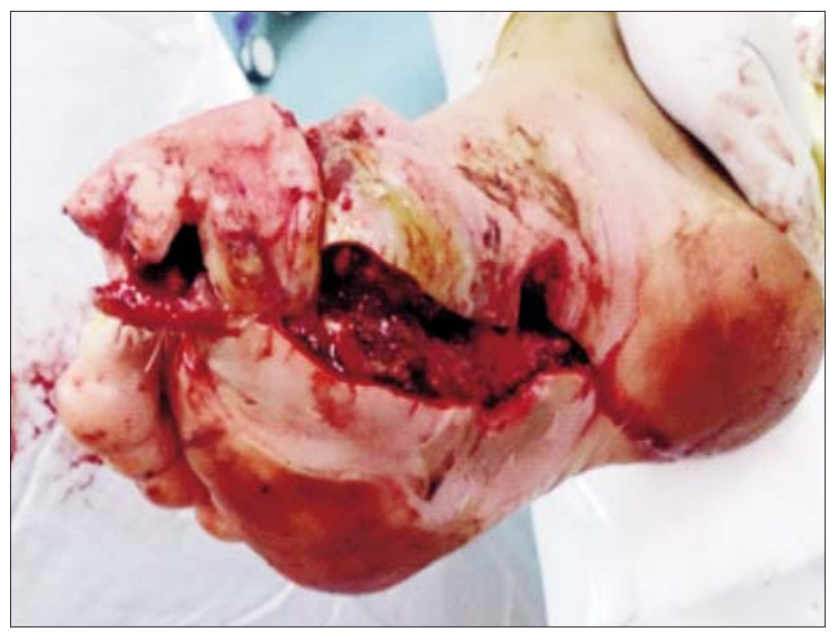

Figure 9

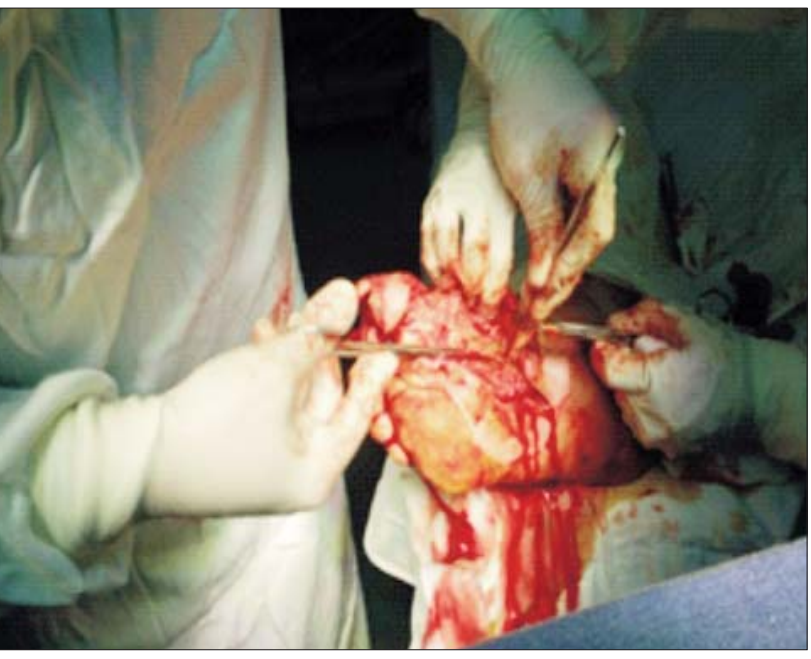

Figure 8

Figure 10 

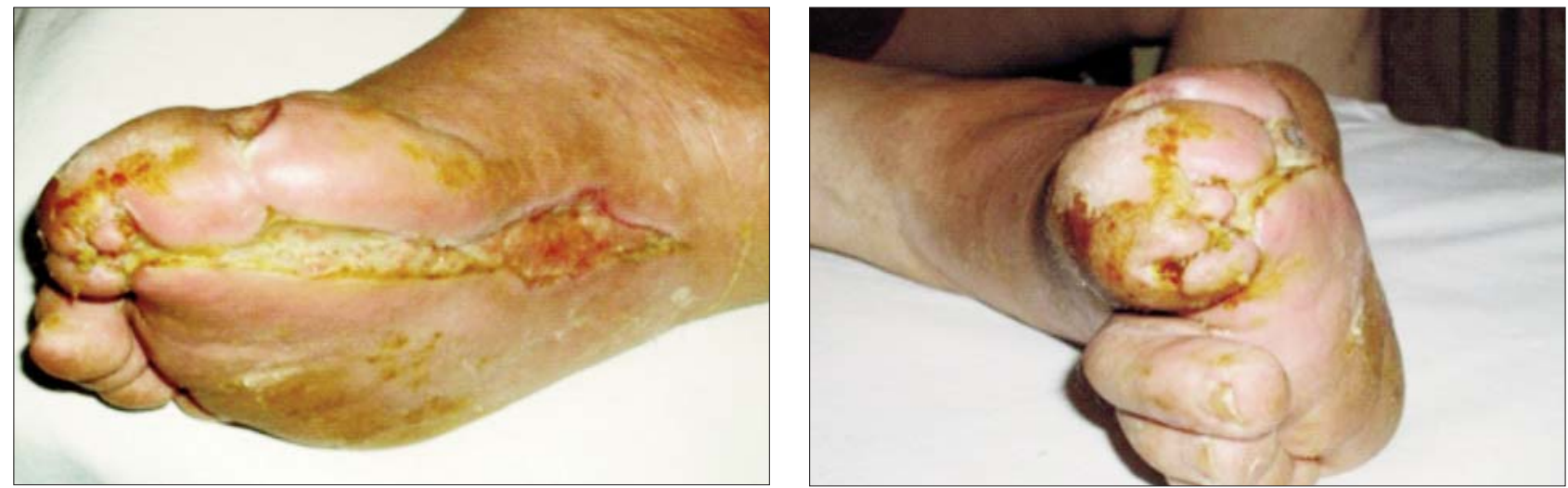

Figure 11

\section{CONCLUSIONS}

Usage of this skin flaps, obtained from the tegumental region of amputated fingers, has several rules:

- diabetic foot should be thoroughly investigated, a good vascularity of the flap should be present, in ischemic cases this process will be used after revascularization;

- lesion type to be evaluated clinically and classified accordingly to international classification;

- surgical treatment should remove all necrotic tissue and well vascularized tissue should be kept;

- these flaps can be kept and used in second surgical timing to cover defects of the skin, when necrotic tissue is incompletely removed and requires repeated debridement.

\section{REFERENCES}

1. Ioannis I. Ignatiadis, MD,, Vassiliki A. Tsiampa, and Apostolos E. Papalois.A systematic approach tothe failed plastic surgical reconstruction of the diabetic foot .Diabetic Foot \& Ankle 2011, 2: 6435 - DOI: 10.3402/ dfa.v2i0.6435.

2. Lavery LA, Armstrong DG, Harkless LB. Classification of diabetic foot wounds. J Foot Ankle Surg 1996; 35: 528 31.

3. Clemens MW, Attinger CE. Functional reconstruction of the diabetic foot. Semin Plast Surg 2010; 24: 43-56.

4. Wild S, Roglic G, Green A, Sicree R, King H. Global prevalence of diabetes: estimates for the year 2000 and projections for 2030. Diabetes Care. 2004 May; 27(5):1047-53

5. Dockery GL. Excisional techniques and procedures. In: Dockery GL, ed. Lower extremity soft tissue and cutaneous plastic surgery. Philadelphia, PA: Saunders-Elsevier; 2006, pp. 71_8.

6. Sherman RA, Sherman J, Gileäd L, Lipo M, Mumcuoglu KY. Maggot debridement therapy in outpatients. Arch Phys Med Rehabil 2001;82:1226-1229.

7. Edgerton MT. The Art of Surgical Technique. Baltimore, MD: Williams and Wilkins; 1988 